\title{
APLICAÇÃO DE IMAGENS TM-LANDSAT NA DETECÇÃO DE ÁGUA OCEÂNICA FRIA E SUA CORRELAÇÃO COM SEDIMENTOS EM SUSPENSÃO E FEIÇÕES TOPOGRÁFICAS SUBMERSAS
}

\author{
T.I.R.Almeida ${ }^{1}$ \\ D.Reinhardt ${ }^{2}$ \\ J.Bonetti Filho ${ }^{2}$ \\ S.A.Ferreira ${ }^{1}$ \\ V.V.Furtado ${ }^{2}$
}

Este trabalho é resultado parcial das atividades de pesquisa de um grupo de pesquisadores que abrange os autores acima, docentes e alunos de graduação dos Institutos de Geociências e Oceanográfico da Universidade de São Paulo. O objetivo geral das pesquisas volta-se a realizar estudos geológicos e oceanográficos em ambientes costeiros e na plataforma continental do Estado de São Paulo, visando a compreensão dos processos quaternários de sedimentação, estudando os princípios de interação e trocas entre sistemas costeiros e a plataforma continental, bem como seu comportamento como um todo durante o Quaternário.

O equipamento utilizado neste trabalho, tanto nas atividades de Sistemas de Informações Georeferenciadas (SIGs) como de processamento de imagens, foi o SITIM-SGI, do Laboratório de Processamento de Imagens e Geoprocessamento (LPI) do Departamento de Geologia Econômica e Geofísica Aplicada do IG-USP. Este processador opera em ambiente PC 486, equipado com placa gráfica produzida pela ENGESPAÇO. Para a entrada de dados batimétricos (Folhas de Bordo 1.600-002/79, 1.640-001/79 na escala de 1:150.000, bem como as Cartas Náuticas 1600, 1613 e 1614, respectivamente nas escalas aproximadas 1:300.000 e as duas últimas em 1:50.000) foi utilizada Mesa digitalizadora DIGIGRAF A0. Como saída gráfica inicial, utilizou-se monitor RGB (1024x768) Videotek de 20", e para os produtos finais, impressora térmica TEKTRONIX 4693DX, todos periféricos do LPI.

A imagem TM-LANDSAT cena 218/76/C de 11/09/1990, foi utilizada nas bandas 1 (0,45-0,52 $\mu \mathrm{m}$ azul, radiação refletida) $2(0,52-0,57 \mu \mathrm{m}$ verde, idem) $3(0,63-0,69 \mu \mathrm{m}$ vermelho, idem) e 6 (10,8-12,5 Infra-vermelho termal, radiação emitida). As três primeiras bandas contam com resolução

\footnotetext{
${ }^{1}$ Departamento de Geologia Econômica e Geofísica Aplicada, Instituto de Geociências, USP.

2 Instituto Oceanográfico, USP.
} 
espacial de $30 \mathrm{~m}$ e última de $120 \mathrm{~m}$. Os processamentos digitais utilizados restringiram-se a manipulações de escala, composições coloridas e realces lineares de contraste, observando-se que apenas a água marinha foi utilizada na obtenção dos histogramas, tendo em vista não haver interesse, nesta fase do trabalho, na porção emersa do continente.

Feições topográficas submersas têm sido largamente utilizadas em estudos sobre flutuações no nivel do mar em plataformas continentais. No Brasil, a partir de Folhas de Bordo da DHN, vêm sendo traçadas manualmente cartas de batimetria de detalhe, sobre as quais selecionam-se perfis representativos para a identificação de escarpas, terraços e vales submersos, que possam sugerir eventos transgressivos/regressivos. O traçado manual, entretanto, é trabalhoso, lento e permite número restrito de representações em planta e perfil, além do problema de compatibilização de escalas diferentes das folhas de bordo.

A utilização de SIGs na elaboração de Modelos Numéricos de Terreno demanda menor tempo e maior precisão na geração de produtos espacialmente referenciados ao eliminar erros sistemáticos inerentes à manipulação manual de grande volume de dados. Permite também grande flexibilidade em opções de elaboração de perfis ou diferentes direções de visada do modelo digital do terreno.

Foram digitalizadas em torno de 15.000 cotas batimétricas, posteriormente organizadas em estrutura que permitiu a geração de uma grade regular com células representativas para uma área de $1 \mathrm{Km}^{2}$, com novos dados batimétricos sendo atribuídos por interpolação estatística para as intersecções da grade.

Como resultados foram obtidos a distribuição de cotas na área em estudo, a carta de isóbatas, mapas hipsométricos, realce de relevo submerso por sombreamento artificial, visualização tridimensional (bloco diagrama) e mapas de declividades e orientação de vertentes.

Sua análise permitiu a identificação de três escarpas que se estendem ao longo de toda a área. A primeira, entre 45 e 50 metros está associada a um período de estabilização do nivel do mar, que na literatura tem sua idade estimada em 11.000 anos B.P. A segunda, a 90 metros, associa-se a 12.000 B.P. e a terceira, a 130 metros, à idade de 18.000 anos B.P. Além destas feições maiores, pode-se visualizar um vale submerso, que à época das regressões deveria representar uma drenagem vinda de Leste (Rio Juqueriquerê e outros) de relativa importância, que passando entre o continente e a Ilha Bela inflete-se para sul, persistindo por pelo menos poucas dezenas de quilômetros. Este vale submerso foi, decerto, invadido preferencialmente ao início das fases transgressivas.

Observou-se, a título de conclusão adicional, a grande versatilidade na utilização de SIGs, baseados em estações de baixo custo para a representação de dados do relevo do fundo marinho, sendo curto o tempo dispendido na elaboração dos resultados, sofrendo novo processo erosivo e posterior atulhamento.

A cena TM-LANDSAT 218 79/C cobre parte da área estudada por SIG, infelizmente pouco avançando para Sul. A banda 6 não processada, referente ao IV termal, não permite a visualização de qualquer feição de interesse, mas, realçada fortemente, adotando-se como níveis de cinza extremos aqueles associados à água do mar local, identificou-se feição linear de temperaturas 
mais baixas, sobre o vale anteriormente identificado. Este fato foi interpretado como a ingressão preferencial de água oceânica associada àquela feição topográfica.

A observação da mesma região nas bandas referentes ao visível mostrou, entretanto, um comportamento baixamente correlacionavel com a banda termal, particularmente no que se refere ao vale acima citado. A compreensão do fenômeno ainda carece de estudos complementares, mas sugere uma dinâmica superficial fortemente influenciada pela costa e não justaposta à outra, mais profunda, de origem oceânica 